\title{
Can exenatide flatten the post-prandial glucose curve in type 1 diabetes?
}

\author{
Charlotte K. Boughton, Roman Hovorka
}

Wellcome Trust-Medical Research Council Institute of Metabolic Science, University of Cambridge, Cambridge, UK

Correspondence to: Charlotte K. Boughton, MD, PhD. University of Cambridge Metabolic Research Laboratories and NIHR Cambridge Biomedical Research Centre, Wellcome Trust-MRC Institute of Metabolic Science, Box 289, Addenbrooke's Hospital, Hills Road, Cambridge CB2 0QQ, UK. Email: cb2000@medschl.cam.ac.uk.

Comment on: Johansen NJ, Dejgaard TF, Lund A, et al. Efficacy and safety of meal-time administration of short-acting exenatide for glycaemic control in type 1 diabetes (MAG1C): a randomised, double-blind, placebo-controlled trial. Lancet Diabetes Endocrinol 2020;8:313-24.

Submitted May 01, 2020. Accepted for publication May 13, 2020.

doi: $10.21037 /$ atm-20-3654

View this article at: http://dx.doi.org/10.21037/atm-20-3654

Attainment of recommended glycaemic control for people with type 1 diabetes (T1D) is challenging and requires lifelong self-management with insulin therapy. Approaches to restore pancreatic beta-cell function to reverse T1D such as islet/pancreas transplant, immunomodulatory therapies and stem cell therapies have not yielded acceptable safety and/or efficacy outcomes (1). Management of T1D therefore focuses on intensive insulin therapy to achieve near normoglycaemia and avoid long-term micro- and microvasculature complications (2). Despite improvements in insulin analogues and advances in diabetes technologies, less than $30 \%$ of people with T1D reach recommended glycaemic targets (3). Intensive insulin therapy is associated with increased risk of hypoglycaemia and weight gain (4).

Even with intensive insulin therapy, management of postprandial hyperglycaemia remains challenging due to delays in subcutaneous insulin absorption. It has been proposed that high glycaemic variability is associated with increased risk of vascular complications in people with T1D (5), although this has not been consistently reported $(6,7)$. Approaches to minimise post-prandial hyperglycaemia and improve glycaemic control, without increasing the risk of hypoglycaemia or weight gain are being pursued.

Anti-hyperglycaemic agents licenced for use in type 2 diabetes (metformin, Glucagon-like peptide-1 (GLP-1) receptor agonists, dipeptidyl peptidase 4 (DPP 4) inhibitors and sodium-glucose transport protein 2 (SGLT2) inhibitors have been considered as candidate therapies to reduce postprandial hyperglycaemia and improve glycaemic control in people with T1D. Several of these medications have favourable effects on weight, cardiovascular and renal systems in people with type 2 diabetes. SGLT2 inhibitors were the first adjunctive therapy to insulin approved for use in Europe in the management of T1D (8), despite being associated with increased incidence of diabetic ketoacidosis in a clinical trial setting (9). Whether these agents also have beneficial cardiovascular and renal profiles in people with T1D has not yet been determined.

GLP-1 receptor agonists mediate their glucose lowering effect through enhanced glucose-dependent secretion of insulin in those with residual beta-cell function, inhibition of glucagon secretion and slowed gastric emptying. They also lower body weight through reduced food intake (10). The beneficial effects of GLP-1 receptor agonists on glycaemic control, body weight and cardiovascular disease have led to recommendations for early use in those with type 2 diabetes and high risk or established cardiovascular disease (11). Previous studies assessing long-acting adjunctive GLP-1 receptor agonists in people with T1D have demonstrated small reductions in HbA1c of $2-3 \mathrm{mmol} / \mathrm{mol}$ and bodyweight loss of 4-6 kg $(12,13)$. However there was increased risk of symptomatic hypoglycaemia and hyperglycaemia with ketosis

The authors of the MAG1C study hypothesised that addition of the short-acting GLP-1 receptor agonist exenatide (Byetta), administered subcutaneously three times a day before meals, as an adjunct to basal bolus insulin injections could improve glycaemic control measured by HbA1c (primary endpoint) by reducing post-prandial glycaemic excursions without increasing the risk of hypoglycaemia, in combination with bodyweight reduction 
in people with T1D (14).

The double blind randomised placebo controlled trial in adults with T1D on multiple daily insulin injections (BMI $>22 \mathrm{~kg} / \mathrm{m}^{2}$ and HbA1 $>59 \mathrm{mmol} / \mathrm{mol}$ ), demonstrated no clinically meaningful effect of prandial exenatide on HbA1c (primary outcome) or post-prandial glycaemic excursions after 26 weeks compared to placebo. Initial improvements in $\mathrm{HbA} 1 \mathrm{c}$ observed at 12 weeks were not sustained at 26 weeks. HbA1c changed by $-3.2 \mathrm{mmol} / \mathrm{mol}(-5.0$ to $-1.4)$ with exenatide and $-2.1 \mathrm{mmol} / \mathrm{mol}(-3.7$ to -0.6$)$ with placebo after 26 weeks, with an estimated treatment difference of $-1.1 \mathrm{mmol} / \mathrm{mol}(-3.4$ to $1.2 ; \mathrm{P}=0.36)$. Mean glucose concentration, time in target glucose range and time in hyper- and hypoglycaemia were also unaffected after 26 weeks and there were no differences in measures of glycaemic variability between the two groups.

The discontinuation rate in the study was high $(21 \%$; 23 of 108) over the 26-week intervention period, and was greater in the exenatide arm $(31 \% ; 17$ of 54$)$ and likely led to the study being underpowered for the primary endpoint. A per protocol analysis did not find any relevant changes in the between-group difference of HbA1c after 26 weeks. The high burden of the study intervention with 3 additional injections per day in a cohort already taking 4-5 injections per day may have played a role, while the differential effect between the two arms also suggests a tolerance issue with exenatide itself, supported by the reporting of frequent gastro-intestinal side-effects. The need for standardised insulin dosing protocols may have been why the protocol excluded those using insulin pump therapy, but given that technology uptake is increasing, the generalisability of the results is limited; retention and adherence may have been improved by including those using pump therapy.

While the MAG1C study demonstrates that adjunctive exenatide has little to offer in terms of glycaemic benefit in T1D, the potential for safe and effective weight loss to reduce cardiovascular risk in those with T1D should not be underestimated. In the MAG1C study, adjunctive prandial exenatide was associated with a body weight reduction of $4.4 \mathrm{~kg}$ and a reduction in total daily insulin dose of 9.0 units per day; a difference attributable to reductions in prandial insulin dose (delayed gastric emptying and suppressed glucagon release) rather than to a direct body weight related reduction in basal insulin dose. Despite significant weight reduction with adjunctive exenatide compared to placebo, there was no increase in the risk of hypoglycaemia after initial insulin dose titration, and in contrast to previous studies with longer-acting GLP-1 receptor agonist liraglutide, there were no episodes of hyperglycaemia with ketosis in this study $(12,13)$. As with other studies of GLP1 receptor agonists, exenatide was associated with increased risk of nausea and vomiting compared with placebo.

Population mean BMI in people with T1D is increasing and the risk of major cardiovascular adverse events increases with increasing BMI (15). Could prandial exenatide be a potential weight management strategy for people with obesity and T1D? With the burden of three additional injections per day, and the adverse gastro-intestinal sideeffects exenatide would likely appeal to only the most motivated of individuals.

Investigation of potential long-term cardiovascular benefits of exenatide, and other GLP-1 receptor agonist in people with T1D requires larger and longer studies and given the high drop-out rate in this study, exenatide is unlikely to be the GLP-1 receptor agonist of choice for this indication.

It is possible that in selected sub-populations with T1D e.g., those with obesity and/or those with residual beta-cell function, adjunctive prandial exenatide may have greater benefits on both glycaemic control and weight loss than observed in this study population. The risks and benefits of this treatment would need to be weighed up on an individual basis. It is unlikely that the favourable effect on weight loss alone is enough to justify adjunctive exenatide for this indication in the general T1D population.

\section{Acknowledgments}

Funding: None.

\section{Footnote}

Provenance and Peer Review: This article was commissioned by the editorial office, Annals of Translational Medicine. The article did not undergo external peer review.

Conflicts of Interest: Both authors have completed the ICMJE uniform disclosure form (available at http://dx.doi. org/10.21037/atm-20-3654). Dr. RH reports grants from JDRF, grants from National Institute for Health Research Cambridge Biomedical Research Centre, grants from Wellcome Strategic Award, grants from NIDDK, grants from H2020, grants from EME NIHR, grants from Helmsley Trust, during the conduct of the study; personal fees from Eli Lilly, personal fees from Novo Nordisk, personal fees from Eli Lilly, personal fees from BBraun, 
personal fees from Medtronic, personal fees from BBraun, personal fees from Novo Nordisk, other from CamDiab, personal fees from Dexcom, outside the submitted work. RH reports having received speaker honoraria from Eli Lilly and Novo Nordisk, serving on advisory panel for Eli Lilly and Novo Nordisk, receiving license fees from B. Braun and Medtronic; having served as a consultant to B. Braun, patents and patent applications related to closedloop, and being shareholder of CamDiab. The other author has no conflicts of interest to declare.

Ethical Statement: The authors are accountable for all aspects of the work in ensuring that questions related to the accuracy or integrity of any part of the work are appropriately investigated and resolved.

Open Access Statement: This is an Open Access article distributed in accordance with the Creative Commons Attribution-NonCommercial-NoDerivs 4.0 International License (CC BY-NC-ND 4.0), which permits the noncommercial replication and distribution of the article with the strict proviso that no changes or edits are made and the original work is properly cited (including links to both the formal publication through the relevant DOI and the license). See: https://creativecommons.org/licenses/by-nc-nd/4.0/.

\section{References}

1. Latres E, Finan DA, Greenstein JL, et al. Navigating Two Roads to Glucose Normalization in Diabetes: Automated Insulin Delivery Devices and Cell Therapy. Cell Metab 2019;29:545-63.

2. Nathan DM, Genuth S, Lachin J, et al. The effect of intensive treatment of diabetes on the development and progression of long-term complications in insulin-dependent diabetes mellitus. N Engl J Med 1993;329:977-86.

3. Foster NC, Beck RW, Miller KM, et al. State of Type 1 Diabetes management and outcomes from the T1D Exchange in 2016-2018. Diabetes Technology \& Therapeutics 2019;21:66-72.

4. Purnell JQ, Zinman B, Brunzell JD. The effect of excess weight gain with intensive diabetes mellitus treatment on cardiovascular disease risk factors and atherosclerosis in type 1 diabetes mellitus: results from the Diabetes Control and Complications Trial/Epidemiology of Diabetes Interventions and Complications Study (DCCT/EDIC) study. Circulation 2013;127:180-7.

5. Beck RW, Bergenstal RM, Riddlesworth TD, et al.
Validation of Time in Range as an Outcome Measure for Diabetes Clinical Trials. Diabetes Care 2019;42:400-5.

6. Lachin JM, Bebu I, Bergenstal RM, et al. Association of Glycemic Variability in Type 1 Diabetes With Progression of Microvascular Outcomes in the Diabetes Control and Complications Trial. Diabetes Care 2017;40:777-83.

7. Kilpatrick ES, Rigby AS, Atkin SL. The effect of glucose variability on the risk of microvascular complications in type 1 diabetes. Diabetes Care 2006;29:1486-90.

8. Agency EM. First oral add-on treatment to insulin for treatment of certain patients with type 1 diabetes. Available online: https://www.ema.europa.eu/en/documents/pressrelease/first-oral-add-treatment-insulin-treatment-certainpatients-type-1-diabetes_en.pdf. 2019.

9. Mathieu C, Dandona P, Gillard P, et al. Efficacy and Safety of Dapagliflozin in Patients With Inadequately Controlled Type 1 Diabetes (the DEPICT-2 Study): 24-Week Results From a Randomized Controlled Trial. Diabetes Care 2018;41:1938-46.

10. Nauck MA, Meier JJ. Incretin hormones: Their role in health and disease. Diabetes Obes Metab 2018;20 Suppl 1:5-21.

11. American Diabetes Association. 9. Pharmacologic Approaches to Glycemic Treatment: Standards of Medical Care in Diabetes-2020. Diabetes Care 2020;43:S98-S110.

12. Mathieu C, Zinman B, Hemmingsson JU, et al. Efficacy and Safety of Liraglutide Added to Insulin Treatment in Type 1 Diabetes: The ADJUNCT ONE Treat-To-Target Randomized Trial. Diabetes Care 2016;39:1702-10.

13. Ahren B, Hirsch IB, Pieber TR, et al. Efficacy and Safety of Liraglutide Added to Capped Insulin Treatment in Subjects With Type 1 Diabetes: The ADJUNCT TWO Randomized Trial. Diabetes Care 2016;39:1693-701.

14. Johansen NJ, Dejgaard TF, Lund A, et al. Efficacy and safety of meal-time administration of short-acting exenatide for glycaemic control in type 1 diabetes (MAG1C): a randomised, double-blind, placebo-controlled trial. Lancet Diabetes Endocrinol 2020;8:313-24.

15. Edqvist J, Rawshani A, Adiels M, et al. BMI, Mortality, and Cardiovascular Outcomes in Type 1 Diabetes: Findings Against an Obesity Paradox. Diabetes Care 2019;42:1297-304.

Cite this article as: Boughton CK, Hovorka R. Can exenatide flatten the post-prandial glucose curve in type 1 diabetes? Ann Transl Med 2020;8(22):1535. doi: 10.21037/atm-20-3654 